\title{
CONF-960994--6
}

IBMM-96 Conference Proceedings - Nuclear Instruments and Methods in Physics Research, Section B

\section{Ion Implantation of Silicon Nitride Ball Bearings}

J. M. Williams

Oak Ridge National Laboratory, Oak Ridge, Tennessee

J. R. Miner

United Technologies, Pratt and Whitney, West Palm Beach, Florida

"The submitted manuscript has been authored by a contractor of the U.S. Government under contract No. DE AC05-960R22464. Accordingly the US. Government retains a nongex the A.S. Governive rople to reproduce the published form of this contribution, or allow others to do so. for U.S. Government purposes."

Prepared by the

Oak Ridge National Laboratory

Oak Ridge, Tennessee 37831 managed by

LOCKHEED MARTIN ENERGY RESEARCH CORP.

for the

U.S. DEPARTMENT OF ENERGY

under contract DE-ACO5-960R22464

September 1996

MASTER

\section{DISTRIBUTION OF THIS DOCUMENT IS UNLIMTED}

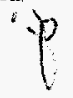




\section{DISCLAIMER}

Portions of this document may be illegible in electronic image products. Images are produced from the best available original document. 
IBMM-96, Reference No. 138

\section{ION IMPLANTATION OF SILICON NITRIDE BALL BEARINGS}

J. M. Williams, Oak Ridge National Laboratory, Oak Ridge, TN 37831

J. R. Miner, United Technologies Corp., Pratt and Whitney, West Palm Beach, FL 33410

A program has existed for determination of the effect of ion implantation on the rolling contact performance of silicon nitride ball bearings. The hypothesis was that stress concentrations reflected into the bulk due to topography such as polishing imperfections, texture in the race, or transferred material, might be reduced due to surface amorphization. Forty-two control samples were tested to an intended runout period of $60 \mathrm{~h}$. Six ion implanted balls were tested to an extended period of $150 \mathrm{~h}$. The bearing test equipment provided for accelerated testing, in a V-groove arrangement, so that wear was on two narrow wear tracks. Other techniques have included Rutherford backscattering, $\mathrm{x}$-ray photoelectron spectroscopy, profilometry, optical microscopy, nanoindentation hardness, and white light interferometry. The balls were implanted with C-ions at $150 \mathrm{keV}$ to a fluence of $1.1 \times 10^{17} / \mathrm{cm}^{2}$. The collection of samples had unanticipated, preexisting, defects called "C-cracks" in the surfaces. As a result, failure rate of the control group was unacceptable. None of the ion-implanted samples experienced failure in $150 \mathrm{~h}$ of testing. The probability of randomly selecting six samples from the control group that would perform this well is about $5 \%$. Therefore, there is good probability that ion implantation improved performance. Possible reasons are discussed. Analytical techniques have been used to characterize ion implantation results, to characterize wear tracks, and to characterize microstructure and impurity content in possible relation to C-cracks.

Contact: J. M. Williams, Oak Ridge National Laboratory, Oak Ridge, TN 37831-6057 USA. phone: 423-574-6265, fax: 423-576-8135, e-mail: QW9@solid.ssd.ornl.gov

\footnotetext{
"The submitted manuscript has been authored by a contractor of the U.S. Government under contract No. DE-AC05-960R22464 Accordingly. the U.S. Government retains a nonexclusive, royalty-free license to publish or reproduce the published form of this contribution. or allow others to do so, for U.S. Government purposes."
} 


\section{Introduction}

The present paper summarizes research, performed under a Cooperative Research and Development Agreement, and designed to investigate the effects of ion implantation on rolling contact performance of engineering silicon nitride ball bearings. The premise of the program is that ion implantation would produce amorphization of the material and would also produce compressive stresses due to swelling and the added atoms. The depth of ion implantation treatment is rather small compared to the depth of projected Hertzian stresses under classical modeling for the nominal geometry. However, analyses in materials mechanics $[1,2,3]$ have shown that surface imperfections of submicron dimension have the effect of superposing severe pressure spikes on the broader Hertzian profile. Thus, suitable properties changes to depths, not exceeding ion ranges, could produce improvement.

There is reason to suspect that $\mathrm{SiC}$ might be a fair paradigm for silicon nitride under ion implantation, but in contrast to $\mathrm{SiC}$, it has not been possible to perform research on single crystals of silicon nitride. Thus, fundamentals are not as well understood for silicon nitride. Silicon carbide is amorphized by small doses under ion implantation, and the hardness and modulus of the affected surface layer decrease [4]. Amorphization is accompanied by swelling [4]. The prevailing view is that ease of amorphization of ceramics increases with increasing covalency of bonding and that silicon nitride should be easily amorphized too. Thus, one would expect that bearing performance might be improved by the amorphous buffer pad, which would have a lower modulus, lower hardness, good isotropy and homogeneity of properties, and compressive stresses.

Ion implantation effects in engineering silicon nitrides have been investigated [5-9], and expectations described are partially confirmed. There is swelling, which may be related to amorphization. Both hardening [6] and softening [7] are reported, depending on ion dose and species. Overall, taking into account the present results and those referenced, there is reason to

suspect that effects may be shifted to higher doses for polycrystalline engineering silicon 
nitrides, in comparison with SiC. Armini et al. [6] provide additional arguments in favor of using ion implantation to improve bearing performance.

Carbon was chosen as the implanted constituent for the present study in hopes of producing less roughening than was observed for $\mathrm{N}[7]$.

\section{Procedures}

\subsection{Material}

The balls were of CERBEC NBD 200 silicon nitride. Forty-two control samples and six ion implanted balls were tested. In addition, one ball was sectioned into flat samples by use of a diamond saw. The flat samples were polished by use of metallographic diamond compound so that the surface roughness was about the same as for the spherical surface of the balls (see below).

The purpose of the flat samples was for trial implantation treatments at a range of doses. It was difficult to make good hardness measurements or topography measurements on the balls themselves. In view of the inconsistencies in the literature as to how the various commercial silicon nitrides responded to ion implantation, it was decided to make the flat samples so that hardness and topography changes due to ion implantation could be better assessed for this particular material.

The balls themselves were of 1.125 in. in diameter, but instead of being completely spherical, they had flatted poles to facilitate the accelerated tests. The ball and test geometry are best described together. The tests were performed by SKF/MRC Bearings, Jamestown, NY, in a testing machine designed by Pratt and Whitney Division of United Technologies Corporation [10]. Figure 1 is a schematic drawing of the test arrangement with the ball. During testing, the ball is constrained to rotate about only one axis by the caging design that makes use of the flatted poles. Rotation is driven by a V-ring wheel with an included angle of $130^{\circ}$. A symmetrical wheel was engaged, so that the wear track is at the azimuth, tangent to the wheels. Loading was via the wheel axles. The driven axle was anchored to balance the 
determined, static load, which was applied via the other wheel. The loaded wheel was free wheeling, with the bearing as idler.

\subsection{Properties and Analyses}

Supporting experimental techniques have included stylus profilometry, white light interferometry, optical microscopy, nanoindentation hardness measurements, X-ray photoelectron spectroscopy (XPS), and Rutherford backscattering spectrometry (RBS).

Scanning white light interferometry was performed by Zygo Corporation by use of a NewView 100 scanning microscope. For this instrument, the interferometer objective is mounted in a piezo scanning device which moves vertically as the sample is scanned. Topography is adduced by use of a Fourier analysis (known as frequency domain analysis) of the multifrequency interferograms. The technique was used to determine smoothness of new balls and to determine the topography of transferred material on the wear track.

Nanoindentation hardness measurements made use of an instrument from Nano Instruments, Inc., which had an indenter of the Berkovich geometry.

RBS made use of standard techniques [11]. Incident ions were 2.0 to $2.3 \mathrm{MeV} \mathrm{He}$ ions. Backscattering angles were approximately $160^{\circ}$.

\subsection{Ion implantations}

Ion implantations were performed by use of a Varian/Extrion 200-1000 ion implantation accelerator, which is a well-known unit with a magnetically analyzed beam. All samples were implanted with singly charged $\mathrm{C}$ ions at $150 \mathrm{keV}$. Flat coupons were implanted by use of a well-calibrated target chamber, which provided for rastering of beam and grid suppression of secondary electrons. Fluences ranged from $3 \times 10^{14} / \mathrm{cm}^{2}$ to $1 \times 10^{17} / \mathrm{cm}^{2}$ in logarithmic increments of about $3 X$. The balls were implanted one-at-a-time by use of a rotating table in the vacuum. During implantation, the ball was fixtured by having it sit on the flatted pole on a pedestal on the rotating table. The entire surface was exposed to the beam, but the relevant dose is only that on the wear track. where the fluence was calculated as 


$$
\Phi\left(\text { ions } / \mathrm{cm}^{2}\right)=\left(\Phi_{\mathrm{f}} \sin \alpha\right) / \pi
$$

where $\Phi_{\mathrm{f}}$ is the fluence on a flat area and $\alpha$ is the azimuthal angle, relative to the flat pole. Retained dose calculations for the geometry were made by use of the code PROFILE [12]. On the basis of the implantation results for the flat samples (see below), it was decided to implant each ball to a carbon fluence of $1.1 \times 10^{17} / \mathrm{cm}^{2}$, which corresponded to a dose of $1.2 \times$ $10^{17} / \mathrm{cm}^{2}$ on the equator. The fundamental range and straggle were 267 and $50 \mathrm{~nm}$. The profile on the equator was spread out towards the surface because of the "unmasked rotating cylinder" effect. Because of the lower incident angle for the track, the profile at the wear track is somewhat more concentrated toward the surface. Sputtering was calculated to have little effect in any situation. Since the ball is a good insulator and rather large, there was some concern about true dosimetry. RBS analyses on the equator, combined with histogram simulation techniques, confirmed that dosimetry was approximately as-expected and that all balls received the same treatment. At half way through each treatment, the chamber was vented and the ball was tumed upside down to ensure that the two tracks received equal fluences. Since it was possible to handle the ball with thin cotton gloves without burning or carbonization, it was concluded that the equilibrium temperature was less than $200^{\circ} \mathrm{C}$.

\subsection{Rolling Contact Wear Tests}

The load on the wheels (Fig. 1) was $1230 \mathrm{lb}$., and the test speed was $7800 \mathrm{rpm}$. The lubricant was Mobil Jet II at $200^{\circ} \mathrm{F}$. The test goal for unimplanted balls was $60 \mathrm{~h}$ and that for implanted balls was $150 \mathrm{~h}$.

\section{Results}

\subsection{Characterizations of unimplanted and implanted materials}

The engineering outcome was dominated by the presence of large topographical features in the whole group of samples. These features, called "C-cracks," were not anticipated when the experiment was designed. During testing, these flaws gave rise to spalls, which resulted in total failure of a statistically unacceptable number of balls. Thus, the whole test group was not 
regarded as acceptable from an engineering standpoint. Figures 2, 3, and 4 illustrate C-cracks and their roles. Figure 2 is a photograph of a C-crack lying almost perpendicular to a wear track, but no spall has occurred. Figure 3 shows a C-crack, lying in a wear track in implanted material, after testing to $150 \mathrm{~h}$, and again, no spall has occurred. However, Fig. 4 shows a spall that has occurred at a C-crack that originally lay somewhat tangential to a wear track. This was for an implanted sample tested to $150 \mathrm{~h}$, but since the spall did not overlap the track, engineering failure did not occur, and the ball was able to finish the test. Two other spalls were found near other wear tracks in implanted tested balls, but no total failures occurred for the six implanted balls out to a test time of $150 \mathrm{~h}$. For the three spalls in implanted material, the crack had large components of direction parallel to the track. No crack contained within a track had a spall in implanted material.

It is difficult to prove that a crack has not been overlooked, when searching a sphere for cracks by optical microscopy, but diligent searching revealed about six cracks per ball, and they ranged up to about $1 \mathrm{~mm}$ in length. These rough statistics were consistent with those obtained by dye penetrant tests at SKF/MRC Bearings. Other than the cracks, the principal micrographic features found were stringers and patches of a "white phase." Morphology was often such as to suggest that cracks might have originated at these stringers (Fig. 5). It has not been possible to microanalyse the phase for composition.

Besides the concentrated areas of white phase, other microstructure generally had a spot texture of under $10 \mu \mathrm{m}$ in dimension, with a few larger white spots, which were assumed to be the sintering aid. Nanoindentation hardness was 15 to $18 \mathrm{Gpa}$, and differences between unimplanted and implanted areas were not detected. Also, differences in hardness between the white spots and the normal area could not be clearly resolved.

There was detectable roughening due to ion implantation, but the roughening was small. Roughening was a topic of concern at the outset because of the possibility that stress concentrations would be enhanced instead of improved. However, for $10^{17} / \mathrm{cm}^{2}$, it was still difficult to find peak-valley differences as high as $10 \mathrm{~nm}$, and arithmetic average surface 
roughness $\left(\mathrm{R}_{2}\right)$ values as low as $6 \mathrm{~nm}$ for $1 \mathrm{~mm}$ traces were found. Values as low as $1.2 \mathrm{~nm}$ were found for unimplanted material. Roughening appeared to be hardly dose dependent above $10^{16} / \mathrm{cm}^{2}$, but swelling was dose dependent. Part of the flat-sample areas were masked during implantation. The ledge height between implanted and unimplanted areas was $20 \mathrm{~nm}$ for $10^{17} / \mathrm{cm}^{2}$. It was decided to process the balls with a high dose to achieve the maximum compressive stress.

RBS analyses were used to confirm implantation treatments, to determine basic composition and impurity levels, and to analyze wear tracks. RBS data were compared with those from NC 132 and NT 154 silicon nitrides. NBD 200 generally had almost no heavy impurities in front of the Si edge, but occasional heavy elements appeared. NC 132 had heavy elements out to the mass of W. NBD 200, supposedly magnesia sintered, had about 4 at. \% of bulk $\mathrm{O}$, but did not have enough $\mathrm{Mg}$ to have reacted that amount of $\mathrm{O}$. Magnesium was not detected by XPS. There was a "roll off" of the RBS Si edge, which could be fitted by assuming $\mathrm{Al}$ as an impurity. Surprisingly, XPS identified $\mathrm{Sn}$ as an impurity, and a compatible small peak was found on some RBS analyses. An impurity that might be identified with the white phase was not unambiguously found.

The visible wear track (Fig. 1) was a film of material transferred to the ball (topography by white light interferometry) with spikes in thickness of up to $1 \mu \mathrm{m}$, and average thickness of about $0.2 \mu \mathrm{m}$. Elemental composition was of $\mathrm{Zn}, \mathrm{P}, \mathrm{O}$, and $\mathrm{C}$, which is what would be expected from transferred lubricant. Transferred Fe from the wheels was also found. Failed bearings had very high Fe because of skidding.

\subsection{Test results}

Unacceptable damage to bearing or V-ring in the test is indicated by noise, skidding, vibration. and fluctuations in drive motor amperage. Seven of the forty-two control samples failed before reaching the desired runout time of $60 \mathrm{~h}$. Figure 3 shows cumulative failures plotted versus sample-hours of running time. The failure rate is approximately linear with a least squares slope of $0.0031 /$ sample-h. Assuming the same failure rate would have applied to 
$150 \mathrm{~h}$, then 16 or 17 of the samples would have failed by then. The random probability of selecting six samples, none of which would fail, is $5 \%$ or less. Thus, from a purely statistical standpoint, there is a high probability that the ion implantation has done some good. This is despite the fact that a few spalls were observed in the neighborhoods of wear tracks for the implanted samples.

\section{Discussion}

Ion implantation was intended to provide further assurance against bearing failure due to stress raisers of much smaller dimensions than $\mathrm{C}$-cracks. Such features could include residual polishing texture, transferred carbonized lubricant in the wear track (as was observed), small adventitious particles, or features on the mating surface, all more or less of dimension not too different from the implantation depth. Now that evidence of improvement against such a gross feature as $\mathrm{C}$-cracks has been found, the question arises as to a credible explanation. It seems likely that crack expansion depends on stress concentrations in relation to fracture properties of material on nanoscale dimensions at the very crack tip, or at nucleate sites in the crack edge where it can change direction. Obviously, cracks are deeper and wider near the middle, but they feather out to essentially zero depth at the tips. If an existing C-crack is subjected to a tensile stress at nearly perpendicular to the prevailing direction of the crack, it is expected that the crack would simply expand via propagation of the tip. If the stress were more biaxial relative to the direction of the crack, the fracture might change directions, ultimately giving rise to a spall. In any case, compressive stresses, introduced by ion implantation, could help arrest crack expansion at the critical nanoscale level of process that exists at crack tips.

The white phase was inhomogeneously distributed, and it is suspected that such distribution of some added constituent, together with properties of that constituent, is the reason for nucleation of the C-cracks. Present RBS and XPS analyses have provided a representation of average composition of the samples, and have indicated some inhomogeneities, but it cannot be proved that the foreign phase has been preferentially analyzed. 


\section{Acknowledgments}

The authors are very grateful to George Hahn for bringing forward the idea of a program in this area. They are also indebted to Zygo Corporation for performing the topography determinations and to MRC/SKF Bearings for the rolling contact tests. Oak Ridge National Laboratory is managed by Lockheed Martin Energy Research Corp. for the U.S. Department of Energy under contract number DE-AC05-960R22464. Research was performed under CRADA agreement 92-0128 between Lockheed Martin Energy Research and United Technologies Corporation, and sponsored by the DOE Energy Research Laboratory Technology Research Program Office.

\section{References}

[1] P. R. Goglia, T. F. Conry, and C. Cusano, J. Tribology 105 (1984) 104.

[2] J. de Mul, M. Vree, and J. Kuypers, J. Tribology 109 (1987) 452.

[3] A. Elsharkaway and B. J. Hamrock, J. Tribology 113 (1991).

[4] C. J. McHargue and J. M. Williams, Nucl. Instr. and Meth. B80/81 (1993) 889.

[5] R. S. Bhattacharya, T. Mah, A. K. Rai, M. G. Mendiratta, and P. P. Pronko, Ion Implantation and Plasma Assisted Processes (conference proceedings) ed. by Robert F. Hochman, Hillary Solnick-Legg, and Keith O. Legg, ASM International, Materials Park, $\mathrm{OH}$ (1988) p83.

[6] A. J. Armini, A. B. Thakker, and J. A. Morrison, Ibid, p89.

[7] D. W. Oblas and V. K. Sarin, Ibid, p95.

[8] D. W. Oblas, V. K. Sarin, and K. Ostreicher, J. Mater. Res. 7 (1992) 2579.

[9] R. S. Bhattacharya, A. K. Rai, and J. M. Williams, J. Appl. Phys. 65 (1989) 676.

[10] A. T. Galbato. Ball Bearing Journal 240 (1992) 26.

[11] W. K. Chu, J. W. Mayer, and M. A. Nicolet, Backscattering Spectrometry, Academic Press, New York, 1978.

[12] A. J. Armini and S. N. Bunker, Mat. Sci. Eng. A115 (1989) 67. 


\section{Figure Captions}

Figure 1. Schematic representation of the rolling contact test principle.

Figure 2. Photograph of a C-crack that happens to lie near a wear track, and is almost perpendicular to the track. Such cracks did not spall. The track is identified as the horizontal striations of transferred material (magnification $=\sim 100$ ).

Figure 3. Photograph of a C-crack that lies entirely within a wear track (magnification = $\sim 100$ ).

Figure 4. A spall initiated at a C-crack that lies just outside a wear track (magnification = -100).

Figure 5. White phase that happens to be distributed in arc-stringer configuration. Some Ccracks appeared to be decorated with such white spots.

Figure 6. Number of engineering failures versus sample-h of running time for the control group. The slope is 0.0031 failures/sample-h. 


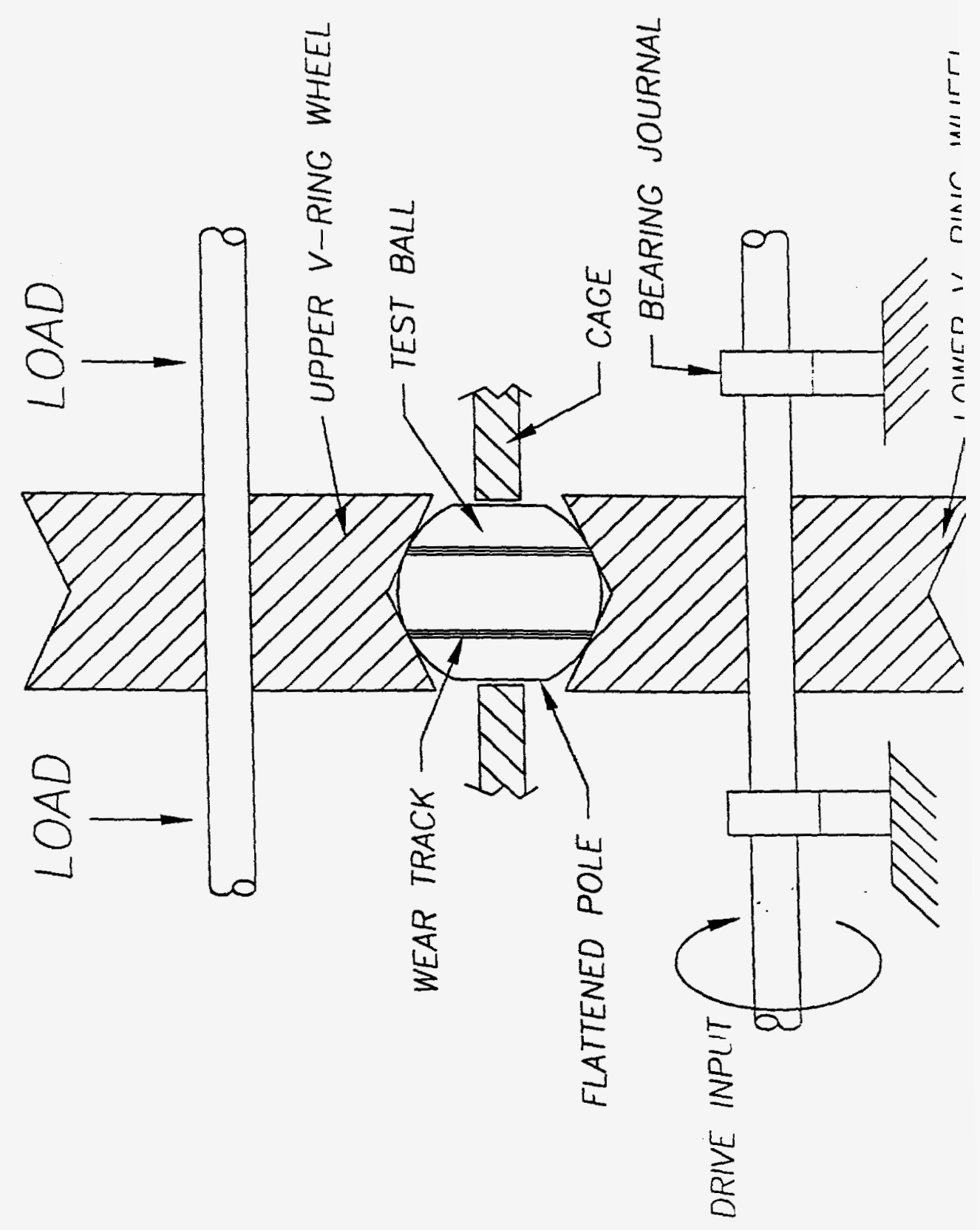




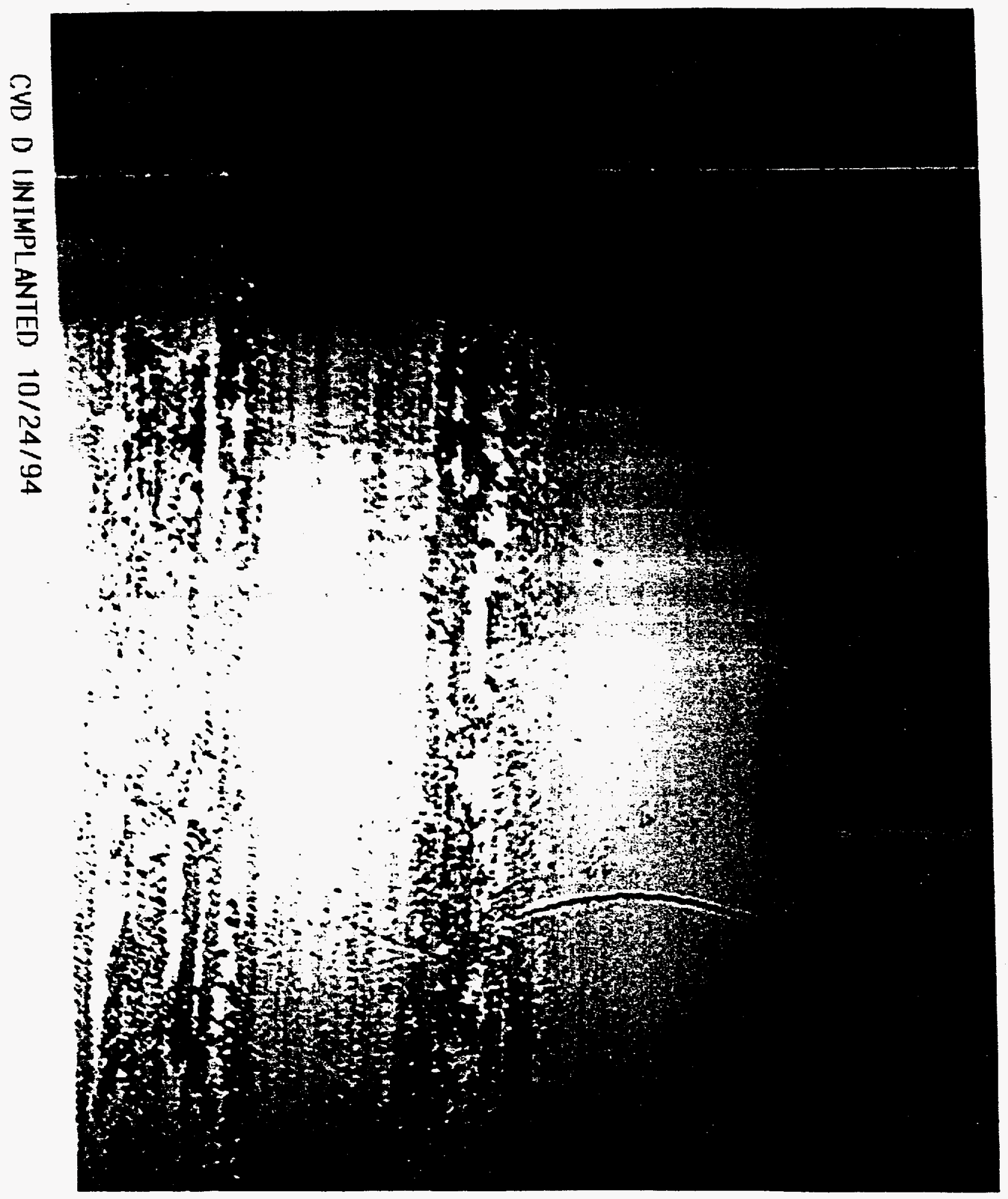




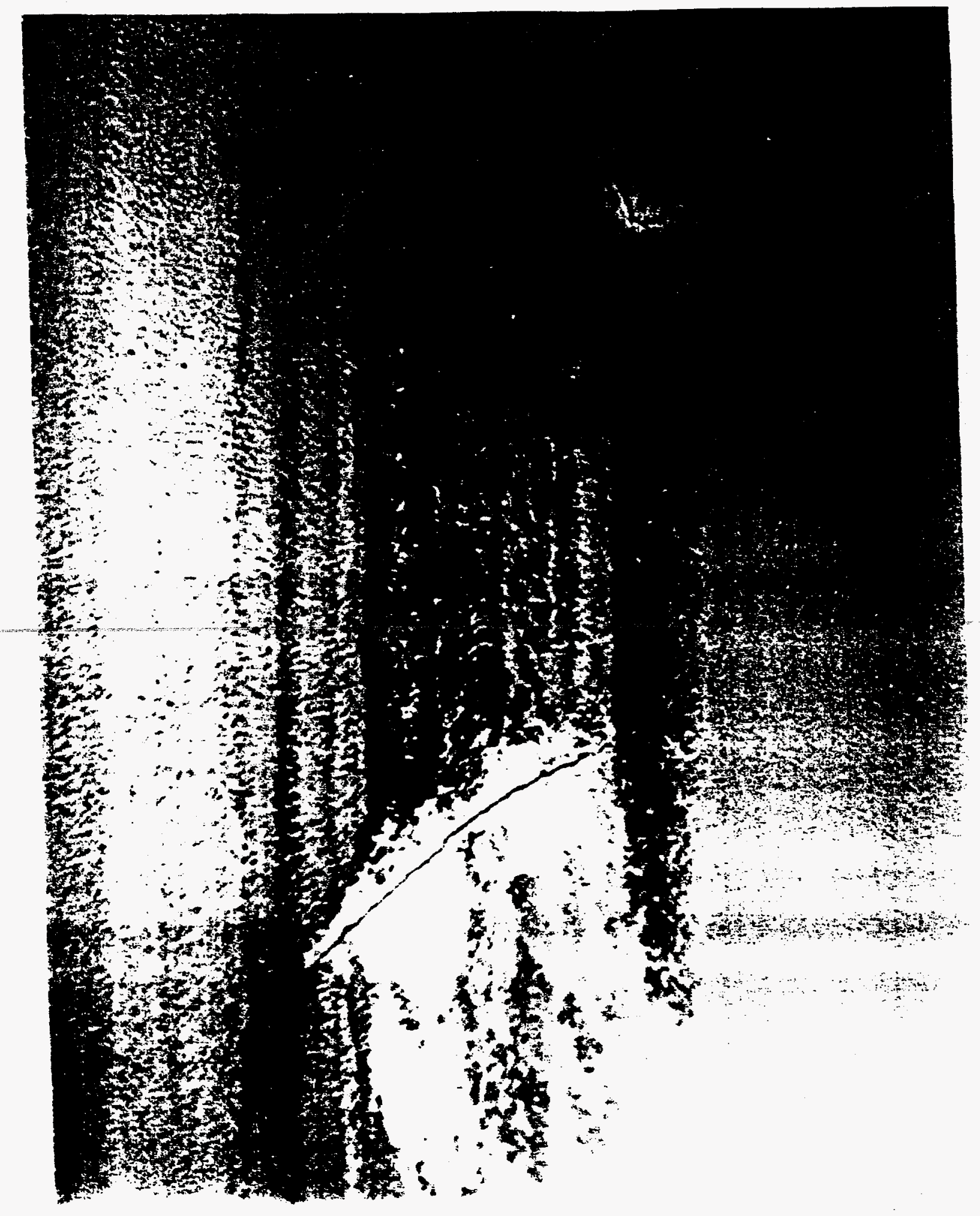




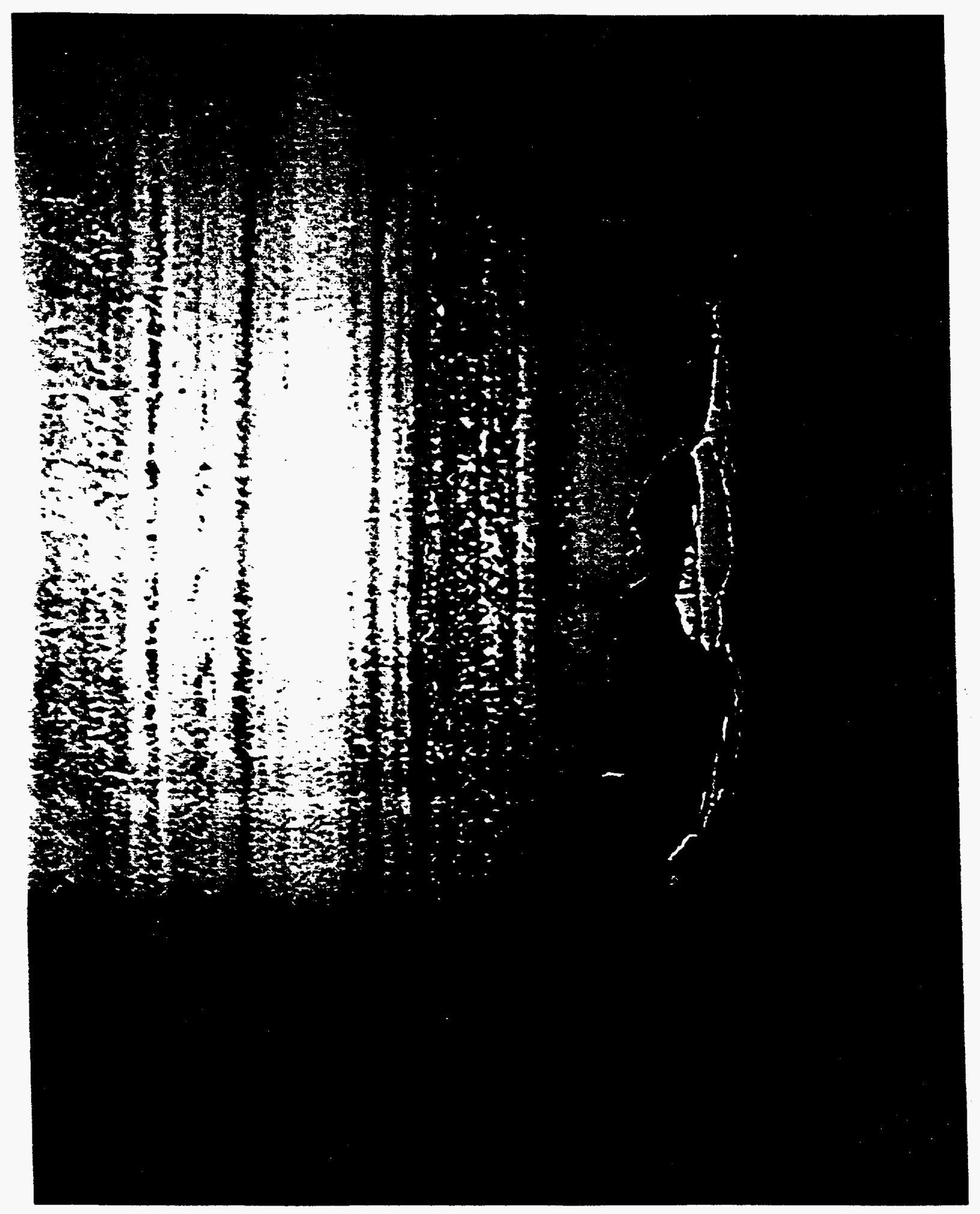




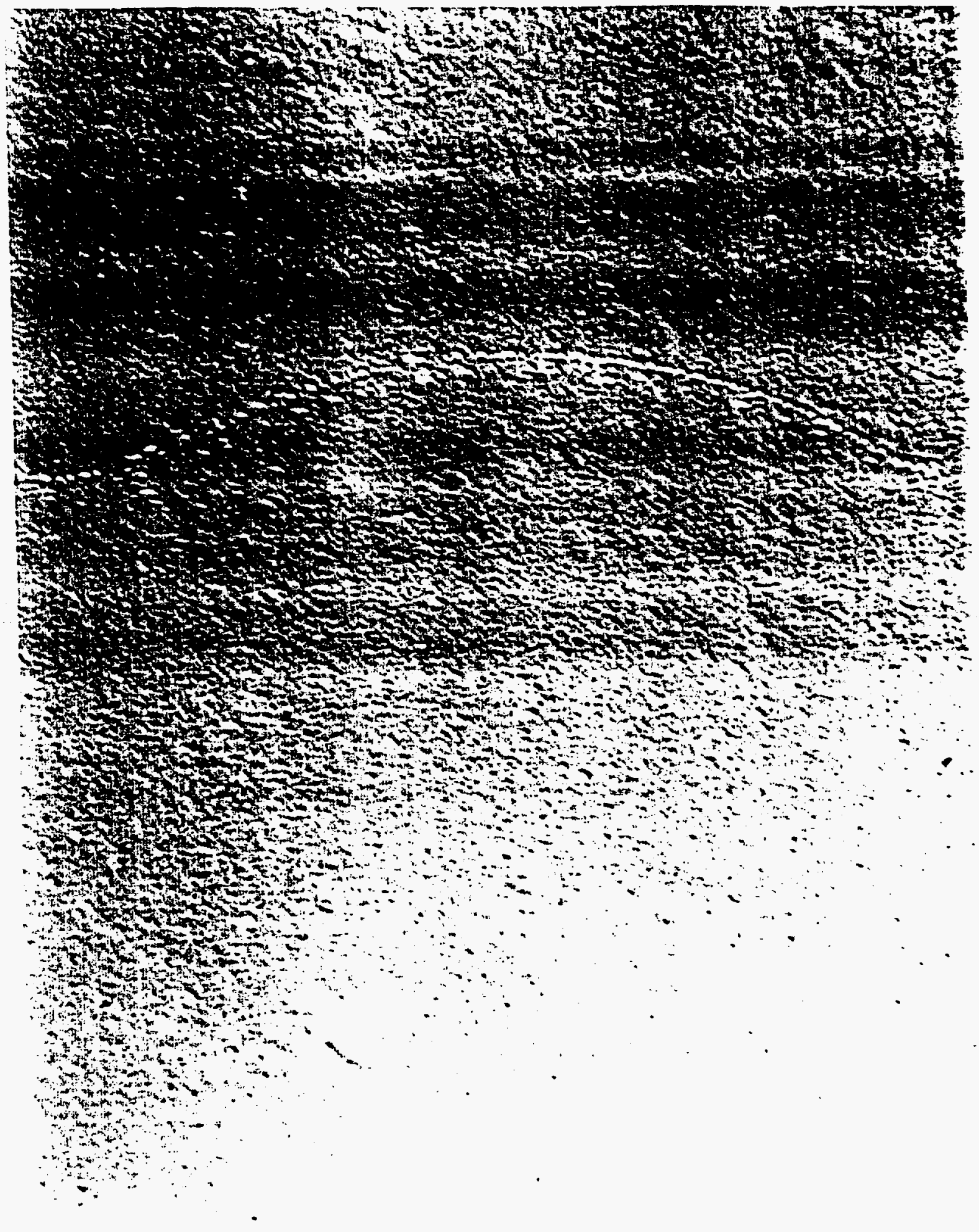




\section{Silicon Nitride Bearings - Unimplanted}

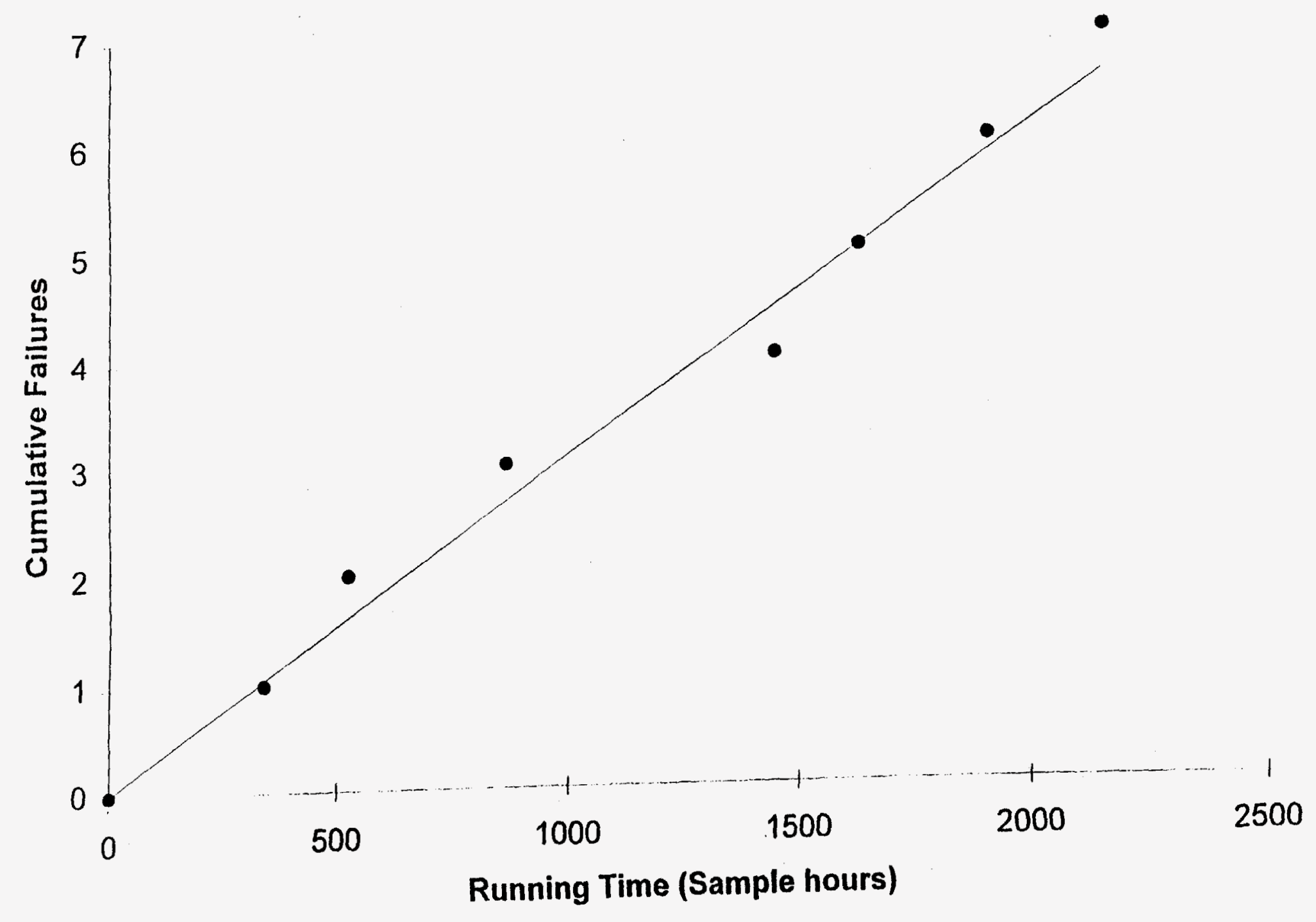

